\title{
A salt-free, zero-discharge and dyebath-recyclable circular coloration technology based on cationic polyelectrolyte complex for cotton fabric dyeing
}

\section{Wen-Yi Wang}

The Hong Kong Polytechnic University

Jia-Chi Chiou

The Hong Kong Polytechnic University

Wan-Xue Chen

The Hong Kong Polytechnic University

Jia-Li Yu

The Hong Kong Polytechnic University

Chi-wai Kan ( $\nabla$ tccwk@polyu.edu.hk)

The Hong Kong Polytechnic University

\section{Research Article}

Keywords: cationic polyelectrolyte complex, sustainable circular dyeing technology, recyclable dyebath, zero effluent discharge, polyhexamethylene biguanide (PHMB)

Posted Date: August 3rd, 2021

DOI: https://doi.org/10.21203/rs.3.rs-735236/v1

License: (c) (1) This work is licensed under a Creative Commons Attribution 4.0 International License. Read Full License

Version of Record: A version of this preprint was published at Cellulose on January 12th, 2022. See the published version at https://doi.org/10.1007/s10570-021-04353-0. 


\section{Abstract}

Textile industry is one of the most polluting industries due to the large quantities of dyeing wastewater it generates and discharges. Herein, we report an eco-friendly and sustainable circular coloration technology based on cationic polyelectrolyte complex to realise salt-free, zero-effluent-discharge circular dyeing for cotton fabrics with a recyclable dyebath by using a typical cationic polyelectrolyte polyhexamethylene biguanide (PHMB) bonded with anionic dyes. The cotton fabrics were first treated with PHMB and then dyed with three commercial acid dyes. Colour measurements show that the colour strength is controllable by adjustment of concentrations of both PHMB and the dyebath. The dyed fabric samples were found to have good/excellent colour levelness $(<0.49)$, and the colour fastness (Grade 3 5 ) was basically satisfactory and acceptable. The dyebath was proved to be recyclable for circular dyeing occurring at room temperature, which greatly reduces consumption of both water and heat energy for textile dyeing. Meanwhile, the dyed fabrics showed antimicrobial activity, particularly for the grampositive S. aureus, which may help reduce the healthcare-associated infections that transmit through textiles. These results suggest that cationic polyelectrolyte-based circular dyeing could provide a promising and practicable strategy to address the pollution issue caused by wastewater generated in dyeing process in the textile industry.

\section{Introduction}

The dyeing of textiles is widely considered as one of the most polluting industry sectors due to the volume and composition of effluents it discharges (Khatri et al. 2015). Apart from a variety of synthetic dyestuffs, textile dyeing also consumes huge volumes of water, energy, and auxiliaries, e.g., salts, electrolytes, acids, alkali/bases, levelling agents, penetrating agents and dispersing agents, which can and does lead to large effluent discharge and causes serious environmental burden and health issues (Burkinshaw and Salihu 2019; Ozturk et al. 2020). It has been reported that the annual consumption of reactive dyes for cellulosic fibres dyeing exceeds 400,000 tons, and up to $50 \%$ of that is discharged into the environment in the form of unutilised or hydrolysed dye, resulting in highly polluting effluents with high oxygen demand and salt load (Xie et al. 2016; Nallathambi and Venkateshwarapuram 2017; Mu et al. 2019). The presence of dyes in aquatic environment is not only aesthetically undesirable but it also causes toxic and carcinogenic effects on living organisms, thereby severely threating the aquatic ecological environment (Zhao et al. 2020).

In order to eliminate effluents and reuse water, numerous studies have been conducted to develop a wide variety of techniques and methodologies for removal of dye from wastewater (Dasgupta et al. 2015; Wang et al. 2021). Examples include adsorption by adsorbents, oxidation, photocatalytic degradation, biological treatment, ozonation, electrochemical treatment, membrane filtration and chemical coagulation/flocculation, etc. (Cai et al. 2021; Ahmad et al. 2015; Vikrant et al. 2018; Yagub et al. 2014; Furlan et al. 2010). Among them, chemical coagulation and flocculation have been widely employed for pretreatment of dyeing wastewater by using cationic polyelectrolyte complex due to its low capital cost and the tailorability (Wilts et al. 2018; Sun et al. 2016). Cationic polyelectrolytes for coagulation and 
flocculation such as cationic polyacrylamides, chitosan and poly(diallyldimethyl ammonium chloride, PDDA) are water-soluble polymers with positively charged moieties on each repeating unit which allow interaction with anionic dye molecules (Meka et al. 2017; Song et al. 2018). Cationic polyelectrolytes have the tendency to form polyelectrolyte complexes with negatively charged ions predominated by the electrostatic interactions, leading to phase separation and formation of stable and insoluble precipitation in most common solvents (Zahrim et al. 2011). Meanwhile, it is the theoretical basis for the spectrophotometric method to quantify quaternary ammonium compounds using a low-molecular anionic dye such as bromophenol blue (Auerbach 1943; Sakai 1983). The anions of aqueous salts of bromophenol blue initially reacts with cationic polyelectrolytes via ion-ion bonding at ambient temperature to form a stable and water-insoluble dye, which is then extracted by chlorinated solvents and thus spectrophotometrically determined (Nand and Ellwood 2018).

On the other hand, cationic polyelectrolytes also find wide applications as cationic agents such as chitosan and PDDA in cationisation of cellulosic fibres to improve dyeability and reactivity by changing the fibre surface charge and thus enhancing dye adsorption (Fang et al. 2015; Correia et al. 2020). Therefore, utilisation of reactive dyes is enhanced while the use of organic salts is reduced or eliminated, thereby contributing to alleviation of pollution resulting from effluent discharge (Arivithamani and Giri Dev 2018; Ma et al. 2020). For example, Dong and coworkers (2020) successfully grafted 2-(N, Ndimethylamino) ethyl methacrylate on the surface of cotton fabrics, and the dyeing showed excellent colour strength, dye uptake, fixation yield and levelness in a low-salt dyeing process by using reactive dye. Acharya et al. (2014) utilised a typical cationic agent, i.e., (3-chloro-2-hydroxylpropyl)trimethylammonium chloride (CHPTAC), to treat cotton fabrics by the exhaustion method, and found that the colour strength and dye uptake with reactive dyes in salt-free dyeing was greatly increased. Fang and colleagues (2013) cationised cotton fabric with the cationic agent acrylamide and improved utilisation of the reactive dyes in salt-free dyeing. Compared with the traditional dyeing process, the dyeing mechanism for cationised cotton fabric with reactive dyes remains unchanged, and it still involves diffusion, penetration, and adsorption of dye molecules onto the fibre. In essence, cationisation of cellulosic fibres functions as inorganic salts (sodium sulphate or sodium chloride) used in traditional cotton dyeing process to promote dye adsorption by reducing the charge repulsion. Actually, even though the researchers claimed that salt-free dyeing process with reactive dyes was performed for the dyeing of cationised cotton fabrics, they still utilised another inorganic salt-sodium carbonate to enhance the dye fixation (Acharya et al. 2014; Fang et al. 2013). Moreover, it is impossible to realise zero discharge of dye wastewater and $100 \%$ utilization of dyes via cationic modification of cotton fabric. The dyebath after dyeing is non-recyclable and needs to be discharged into the environment. Consequently, it is essential to develop an ecologically sustainable and economical dyeing technology to address the pollution issue associated with effluent discharge in textile dyeing.

Additionally, another widespread application of cationic polyelectrolytes in textile industry is used as antimicrobial agents such as polyhexamethylene biguanide (PHMB) due to its high biocidal ability, hypotoxicity and reasonable cost (Simoncic and Tomsic 2010; Wang and Kan 2020). Blackburn and coworkers (2006) demonstrated that the adsorption mechanism of PHMB on cellulosic fibre follows the 
Langmuir isotherms at low concentrations with the formation of monomolecular layer, whereas at higher concentrations it shows the characteristics of the Freundlich isotherms, leading to stacking of multilayer PHMB molecules via electrostatic interaction and hydrogen bond. Moreover, owing to the small molecule diameter (22 ̊), PHMB molecules can diffuse into the inner pores of the cellulose fibres ( $80 \AA$ ) (Wågberg and Hägglund 2001; Blackburn et al. 2006). This could be responsible for the strong affinity of PHMB molecules to cellulosic fibres and the good durable properties of PHMB treated cellulosic fabrics in resistance to abrasion during wearing and household washing (Cao et al. 2020; Chen-Yu et al. 2007). Bhaskara et al. (2021) studied the kinetics of adsorption and desorption of PHMB on cotton fabrics and concluded that nearly zero desorption PHMB was observed from the surface of cotton fabrics at low concentrations. The underlying reason may consist in both the electrostatic interaction and diffusion of PHMB molecules into the inner cores of cellulose fibres.

Based on our previous findings (Wang and Kan 2020; Wang et al. 2021), we are motivated to develop an environment-friendly dyeing method with recyclable dyebath and zero effluent discharge (Fig. 1), considering the stable and insoluble precipitation stoichiometrically formed between anionic dyes and cationic polyelectrolytes at room temperature. The dyeing heavily depends on the stoichiometric reaction predominated by electrostatic force between positively charged polyelectrolytes and negatively charged dye molecules and can occur at room temperature without addition of inorganic salts, which enables the dyebath to be completely recyclable without being discharged into the environment. As shown in Fig. 1, the cellulosic fabric is initially treated with cationic polyelectrolytes and then dyed with anionic dyes at room temperature; after first dyeing, the dyebath is recycled for the second and/or third dyeing. The dyebath is replenished for circular dyeing if concentration of dyebath becomes too low after serial dyeings.

This study aims to explore feasibility and applicability of the above proposed proof-of-concept. The representative antimicrobial agent PHMB was selected as the model cationic polyelectrolyte to treat cotton fabrics, which were then dyed with three commercial anionic acid dyes commonly used to dye wool and silk that contain many cationic sites (protonated $-\mathrm{NH}_{2}$ groups). The dyed fabric samples were evaluated by a series of analytical techniques in terms of colour strength, colour levelness and dyebath recyclability for circular dyeing.

\section{Experimental}

\section{Materials}

Desized and scoured plain-woven $100 \%$ cotton fabric (fabric weight $175 \mathrm{~g} / \mathrm{m}^{2}$ ) was used for this study. Polyhexamethylene biguanide (PHMB) was procured from Breakthrough Textiles Co., Ltd (Taipei City, Taiwan) as a $20 \% \mathrm{w} / \mathrm{v}$ aqueous solution. C13-oxoalcoholethoxylates (7EO) used as nonionic detergent was supplied by SDC Enterprises Limited, Holmfirth, UK. Three model anionic dyes C.I. Acid Red 127, C.I. Acid Blue 83 and C.I. Acid Black 172 were obtained from Shanghai Anoky Group Co., Ltd. (China). Chemical structures of PHMB and the three anionic acid dyes are given in Fig. 2. 


\section{PHMB coated onto cotton fabrics}

Cotton fabric specimens $(20 \times 30 \mathrm{~cm})$ were initially exhausted in prediluted PHMB solutions $(0.2 \%$ and $0.4 \% \mathrm{w} / \mathrm{v}$ ) for 5 minutes to achieve uniform deposition, and then padded in a laboratory-scale horizontal roller with a wet uptake of $80 \%$. Afterwards, the samples were dried at $90^{\circ} \mathrm{C}$ for 2 minutes, followed by curing for 1 minute at $140^{\circ} \mathrm{C}$. The specimens prepared with PHMB solutions of $0.2 \%$ and $0.4 \%(\mathrm{w} / \mathrm{v})$ were labelled as $\mathrm{PHO} 2$ and $\mathrm{PH} 04$, respectively.

\section{Dyeing}

The dyebath (300 mg/L, $500 \mathrm{mg} / \mathrm{L}$ ) of three model acid dyes was prepared before dyeing. PHMB-coated cotton fabrics (PH02, PH04) were directly dipped in the dyebath (liquor ratio 50:1) at ambient temperature for 1 hour. Then, the dyed fabrics were withdrawn and washed with copious running water to remove the unfixed dyes. Afterwards, the dyed cotton fabrics were dried in air. Suffixes -300 and -500 , related to $300 \mathrm{mg} / \mathrm{L}$ and $500 \mathrm{mg} / \mathrm{L}$ dye concentration respectively, distinguish the PH02 and PH04 samples in the following discussion, i.e., $\mathrm{PH} 02-300, \mathrm{PH} 2-500, \mathrm{PH} 04-300$, and $\mathrm{PH} 04-500$.

\section{Recycled dyebath for circular dyeing}

To validate the reusability of recycled dyebath (circulating dyeing), the $500 \mathrm{mg} / \mathrm{L}$ dyebath of three acid dyes after first dyeing of $\mathrm{PHO} 2$ was collected and reused for circular dyeing (Fig. 1). The samples were named PH02-1, PH02-2 and PH02-3 for first, second and third dyeing processes (with the same bath) in

Fig. 1, respectively. After the third dyeing, the dyebath was replenished to maintain original concentration for circular dyeing, i.e., PH02-4. The conditions for dyeing remained unchanged, and the concentration of dyebath was spectrophotometrically determined after each dyeing.

\section{Fourier transform infrared (FTIR) analysis}

FTIR analysis was carried out to validate the presence of PHMB on the cotton fabrics after being treated with PHMB by using Spectrum 100 FT-IR Spectrometer (Perkin Elmer, USA).

\section{Dye uptake}

A calibration curve of each dye was established in advance. After dyeing, the concentration of residual dyebath was determined by using a UV-visible double-beam spectrophotometer (UH5300, Hitachi, Tokyo, Japan) at $\lambda$ max of each dye. The dye uptake was calculated according to Eq. (1).

Dye uptake $(\%)=\left(1-C_{1} / C_{0}\right) \times 100(1)$

Where $\mathrm{C}_{0}$ and $\mathrm{C}_{1}$ are the dyebath concentrations before and after dyeing, respectively.

\section{Colour strength evaluation}

The colour strength, or colour yield of the dyed fabrics, i.e., so-called K/S value, was evaluated by using a spectrophotometer (GretagMacbeth Color Eye 7000A) based on the Kubelka-Munk equation (Eq. (2)), 
where $\mathrm{K}, \mathrm{S}$, and $\mathrm{R}$ denote the absorption coefficient, the scattering coefficient, and the reflectance value of the coloured samples, respectively. The testing was conducted and averaged at three different locations on the surface of each specimen after it was folded twice.

$K / S=(1-R)^{2} / 2 R(2)$

\section{Colour levelness properties}

The relative unlevelness index (RUI), developed by Chong et al. (1992), is the most frequently used method to evaluate the colour levelness of dyed fabrics. By this method, the lower the RUI value, the better the colour levelness is. It means excellent visual levelness if RUI value is less than 0.2 ; the colour levelness is regarded as good if $\mathrm{RUI}$ ranges from 0.2 to 0.49 ; the rating of visual levelness is poor if $\mathrm{RUI}$ ranges from 0.5 to 1.0 ; while bad visual levelness is graded if RUI value exceeds 1.0.

\section{Fastness assessment}

Colour fastness to rubbing of the dyed samples were examined in accordance with AATCC TM8-2016e, and the colour fastness to laundering was evaluated by the standard method of AATCC TM61-2013 (Test No. $1 \mathrm{~A}$ ) with a slight amendment by using the nonionic detergent C13-oxo alcohol ethoxylates in place of the proposed anionic detergent in order to minimize the potential impacts.

\section{Antimicrobial activity evaluation}

The antimicrobial behaviour of fabric samples against the gram-positive Staphylococcus aureus ( $S$. aureus) and the gram-negative Klebsiella pneumoniae (K. pneumoniae) before and after dyeing with acid dyes were qualitatively evaluated by using AATCC TM 147-201, as reported in previous publication (Wang and Kan 2020). The average width of the inhibition zone was obtained according to Eq. (3).

$W=(T-D) / 2(3)$

Where $\mathrm{W}, \mathrm{T}$, and $\mathrm{D}$ represent the width of inhibition zone in $\mathrm{mm}$, the total diameter of the specimen and inhibition zone in $\mathrm{mm}$, and the diameter of the specimen in $\mathrm{mm}$, respectively.

\section{Results And Discussion}

\section{Surface analysis}

The change in chemical structure of surface of cellulosic fibres after being coated with PHMB was assessed by FTIR analysis. As expected, a strong absorbance with a sharp peak at $1543 \mathrm{~cm}^{-1}$ is observed in Fig. 3(a). This is attributed to the characteristic absorption of imine group $(-\mathrm{C}=\mathrm{N}-)$ of PHMB molecule (Gao et al. 2011). The wide double absorption bands at $3175 \mathrm{~cm}^{-1}$ and $3304 \mathrm{~cm}^{-1}$ are due to stretching vibration of amine groups $\left(-\mathrm{NH}-\right.$ and $\left.-\mathrm{NH}_{2}-\right)$, whereas another double peak observed at 2856 $\mathrm{cm}^{-1}$ and $2930 \mathrm{~cm}^{-1}$ results from the asymmetrical and symmetrical stretching vibration of $-\mathrm{CH}_{2}$ group (Worsley et al. 2019). Compared with the control sample, i.e., untreated cotton fabric, the characteristic 
absorption band at $1544 \mathrm{~cm}^{-1}$ and the double peak at $2850 \mathrm{~cm}^{-1}$ and $2917 \mathrm{~cm}^{-1}$ are observed on the samples after being treated with PHMB, indicating the existence of PHMB after coating on the surface of fabric samples. Moreover, the band shift of PHMB results from electrostatic attraction between PHMB and cellulose molecules.

Cellulosic fabrics are generally dyed with reactive dye and direct dyes, whereas acid dyes are commonly used to dye wool and silk that contain many cationic sites (protonated $-\mathrm{NH}_{2}$ groups) by hydrogen bonding, Van der Waals' forces or ionic bonding. Therefore, dyeing of cotton fabrics with acid dyes provide further evidence that PHMB was successfully coated onto the fabrics (Fig. 3b). Moreover, the colour shade not only depends on concentration of PHMB for treating cellulosic fibres, but also relates to concentration of the dyebath. The reason could be the stoichiometric reaction between anionic dye molecules and cationic polyelectrolyte, which suggests that the colour shade is controllable. Figure $3 \mathrm{c}$ displays the underlying dyeing mechanism between anionic dye molecules and cationic polyelectrolyte, which markedly differs from the traditional cotton dyeing methods involving diffusion, penetration, and adsorption of dye molecules. The stoichiometric reaction between anionic dye molecules and cationic polyelectrolyte makes it possible to reuse the dyebath for circular dyeing, thereby achieving zero effluent discharge. Furthermore, this reaction can occur at room temperature, which implies that heat energy is not a necessity for textile dyeing.

\section{Colour measurement of dyed samples}

The reflectance value of a colour depends on its ability to reflect the visible light, which means that the reflectance value varies inversely with the colour strength. Figure 4 shows the reflectance values of PHMB modified cellulosic fibres dyed with three model acid dyes. Clearly, a similar tendency was obtained in the reflectance curves of dyed samples for each dye, and there is not any band shift, which means that the colour shade for all the three acid dyes remained unchanged. The lowest reflectance value for acid red is $510 \mathrm{~nm}$, while values for acid blue and acid black are $590 \mathrm{~nm}$ and $580 \mathrm{~nm}$, respectively.

For C.I. Acid Red 127 (Fig. 4(a, b)), the sample PH02-300 presents the maximum reflectance value, which indicates that $\mathrm{PH} 02-300$ is the lightest in terms of colour depth. As concentration of the dyebath grew from $300 \mathrm{mg} / \mathrm{L}$ to $500 \mathrm{mg} / \mathrm{L}$, reflectance value of the sample (PH02-500) declined. Similar trends are also observed in PH04-300 and PH04-500 samples, which indicates that the reflectance is dependent on dyebath concentration. Compared to $\mathrm{PH} 02-300, \mathrm{PH} 04-300$ has a lower reflectance value, whereas this value for PH04-300 is higher than that of PH04-500. This demonstrates that the value of reflectance varies inversely with the concentration of $\mathrm{PHMB}$ attached on the cotton fabric. Similar results were also achieved in C.I. Acid Blue 83 (Fig. 4(c, d)) and C.I. Acid Black 172 (Fig. 4(e, f)).

Colour strength of dyed samples can be calculated from the reflectance curves, according to Eq. (1). Table 1 shows the maximum K/S value for each sample, which corresponds to the minimum reflectance value. A higher $\mathrm{K} / \mathrm{S}$ value means the more dye bonded with the cationic polyelectrolyte. Clearly, for all the samples, the value of K/S shows a positive relationship with dyebath concentration; it increases with an 
increase in the concentration of dyebath from $300 \mathrm{mg} / \mathrm{L}$ to $500 \mathrm{mg} / \mathrm{L}$, which suggests that the sample dyed with $500 \mathrm{mg} / \mathrm{L}$ dyebath had a darker shade than that dyed with $300 \mathrm{mg} / \mathrm{L}$ dyebath. This could be due to the fact that a higher concentration of dyebath offers more anionic dye molecules that bond with cationic sites. Comparing PHO2 and PH04, the latter presented a higher $\mathrm{K} / \mathrm{S}$ value for the same concentration of dyebath, indicating that the colour strength is positively associated with the content of cationic polyelectrolytes coated onto cellulosic fibres. These results agree with those observed in Fig. $3 \mathrm{~b}$.

Table 1

Colour strength (K/S value) of PHMB treated cotton fabrics after dyeing with three acid dyes at different concentrations

\begin{tabular}{|lllll|}
\hline $\begin{array}{l}\text { Samples } \\
\text { Dyebath }\end{array}$ & PH02-300 & PH02-500 & PH04-300 & PH04-500 \\
\hline C.I. Acid Red 127 & 1.86 & 2.29 & 2.40 & 2.67 \\
\hline C.I. Acid Black 172 & 2.49 & 3.13 & 3.34 & 3.63 \\
\hline C.I. Acid Blue 83 & 2.44 & 2.67 & 3.03 & 3.34 \\
\hline
\end{tabular}

Next, we evaluated the colour levelness which is commonly used for describing the dyeing quality by using the relative unlevelness index (RUI). Table 2 displays that all the dyed fabric samples with acid dyes show good and excellent visual uniformity, which suggests that the nonuniformity of colour shade is imperceptible to the naked eye and is merely detectable by specialised equipment under close inspection. Actually, since dyeing principally occurs between acid dye molecules and the cationic polyelectrolyte $\mathrm{PHMB}$, evenness of deposition of PHMB on the cellulosic fabric is of high importance and dominates the levelness of the dyed fabrics. At high concentration, PHMB molecules may form multilayer adsorption via layer-by-layer assembly on the surface of cellulosic fibres (Blackburn et al. 2006), which may impede bonding of dye molecules resulting from steric hindrance effect and lead to colour unlevelness. Meanwhile, this explains why we used low concentrations of PHMB to modify cellulosic fabric via exhaustion, the purpose of which is to deposit PHMB uniformly onto the cellulosic fibres. 
Table 2

RUI value of cotton fabrics coated with PHMB after dyeing with three acid dyes at different concentrations

\begin{tabular}{|c|c|c|c|}
\hline & \\
\hline Sample & & RUI & Rating \\
\hline \multirow[t]{4}{*}{ C.I. Acid Red 127} & PH02-300 & 0.27 & Good levelness \\
\hline & $\mathrm{PH} 04-300$ & 0.23 & Good levelness \\
\hline & PH02-500 & 0.17 & Excellent levelness \\
\hline & PH04-500 & 0.19 & Excellent levelness \\
\hline \multirow[t]{4}{*}{ C.I. Acid Black 172} & PH02-300 & 0.06 & Excellent levelness \\
\hline & PH04-300 & 0.49 & Good levelness \\
\hline & PH02-500 & 0.25 & Good levelness \\
\hline & $\mathrm{PH} 04-500$ & 0.127 & Excellent levelness \\
\hline \multirow[t]{4}{*}{ C.I. Acid Blue 83} & PH02-300 & 0.13 & Excellent levelness \\
\hline & PH04-300 & 0.28 & Good levelness \\
\hline & PH02-500 & 0.05 & Excellent levelness \\
\hline & $\mathrm{PH} 04-500$ & 0.29 & Good levelness \\
\hline
\end{tabular}

Based on the above discussion, we investigated reusability of the dyebath for the proposed circular dyeing in the following experiments. Contents of the dyebath of $500 \mathrm{mg} / \mathrm{L}$ after first dyeing of PHO2 were reused for second and third dyeing and were then replenished for the next round of dyeing.

Spectrophotometric method was employed to determine the concentration of dyebath after dyeing and the corresponding dye uptake. Figure 5(a) exhibits that the maximum absorption peaks are at $500 \mathrm{~nm}$ and $569.8 \mathrm{~nm}$, respectively, for C.I. Acid Red 127 and C.I. Acid Black 172, while C.I. Acid Blue 83 shows double absorption peaks in visible spectra, i.e., $590 \mathrm{~nm}$ and $630 \mathrm{~nm}$. Based on the maximum absorption, standard calibration curves of the three dyestuffs were established according to the Beer-Lambert's law, all of which show high correlation $\left(R^{2}>0.99\right)$ Fig. 5(b).

Figure 5(c) shows colour strength (K/S value) obtained in circular dyeing of $\mathrm{PH} 02$ in $500 \mathrm{mg} / \mathrm{L}$ dyebath. Clearly, for three acid dyes, there was a slight decrease in colour strength after the second and third dyeing using the recycled dyebath. This could be related to the decrease in concentration of dyebath after dyeing. After first dyeing, the dye uptake for C.I. Acid Black 172, C.I. Acid Red 127, and C.I. Acid Blue 83 was around $16 \%, 21 \%$, and $25 \%$, respectively (Fig. 5 d). This implies that the dyebath concentration was reduced to $420 \mathrm{mg} / \mathrm{L}, 395 \mathrm{mg} / \mathrm{L}$, and $375 \mathrm{mg} / \mathrm{L}$, respectively, from the original $500 \mathrm{mg} / \mathrm{L}$ after first dyeing. These dyebaths were collected for circular dyeing, and dye uptake increased to $40 \%, 45 \%$ and $57 \%$ for C.I. Acid Black 172, C.I. Acid Red 127 and C.I. Acid Blue 83, respectively, after using the dyebath thrice. 
Accordingly, concentration of dyebath declined to $300 \mathrm{mg} / \mathrm{L}, 275 \mathrm{mg} / \mathrm{L}$ and $215 \mathrm{mg} / \mathrm{L}$ for C.I. Acid Black 172, C.I. Acid Red 127 and C.I. Acid Blue 83, respectively. Then, the dyebath was replenished to maintain the concentration at $500 \mathrm{mg} / \mathrm{L}$ for the next round of dyeing, i.e., PH02-4, the fourth dyeing (Fig. 5c). For three acid dyes, there is no significant difference between colour strength in the circular dyeing and the $\mathrm{K} / \mathrm{S}$ value of $\mathrm{PHO} 2-4$ was very close to that of $\mathrm{PH} 02-1, \mathrm{PH} 02-2$ and $\mathrm{PH} 02-3$, which demonstrates that the dyebath is recyclable.

\section{Fastness properties}

Colour fastness is a term used for measuring and describing ability of the colour to withstand fading and staining when in use. In the present study, we investigate two of the most representative colour fastness measures, i.e., rubbing fastness and washing fastness (Table 3). Regarding the rubbing fastness, clearly, all the fabric samples showed excellent fastness to dry rubbing, reaching Grade 5. However, it was found that the wet rubbing fastness was slightly poorer, with the Grade above 3. For the fastness to laundering, it denotes the resistance of coloured fabrics against colour fading during household washing. In the present study, the colour change and staining of dyed fabrics after laundering were evaluated. Clearly, colours of all samples show a slight variation after washing, with Grade rating of above 4, while the colour staining was of rating 5 . This demonstrates that the dyed samples have satisfactory and acceptable colour fastness properties, which implies that cationic polyelectrolyte-based dyeing strategy could be a practicable alternative and circular dyeing without effluent discharge is feasible. This may help mitigate the pollution caused by textile dyeing wastewater.

Table 3

Colour fastness of PHMB treated cotton fabrics after dyeing with three acid dyes

\begin{tabular}{|c|c|c|c|c|c|c|c|c|}
\hline \multirow{2}{*}{$\begin{array}{l}\text { Dyebath (mg/L) } \\
\text { Colour fastness }\end{array}$} & & & \multicolumn{2}{|c|}{ Acid Red } & \multicolumn{2}{|c|}{ Acid Black } & \multicolumn{2}{|c|}{ Acid Blue } \\
\hline & & & 300 & 500 & 300 & 500 & 300 & 500 \\
\hline \multirow[t]{4}{*}{ Rubbing fastness } & \multirow[t]{2}{*}{$\mathrm{PHO} 2$} & Dye & 5 & 5 & 5 & 5 & 5 & 5 \\
\hline & & Wet & $3-4$ & $3-4$ & $3-4$ & $3-4$ & $3-4$ & $3-4$ \\
\hline & \multirow[t]{2}{*}{$\mathrm{PHO4}$} & Dye & 5 & 5 & 5 & 5 & 5 & 5 \\
\hline & & Wet & $3-4$ & $3-4$ & $3-4$ & 3 & $3-4$ & $3-4$ \\
\hline \multirow[t]{4}{*}{ Wash fastness } & \multirow[t]{2}{*}{ Colour change } & $\mathrm{PH} 02$ & 4 & 4 & 4 & 4 & 4 & 4 \\
\hline & & $\mathrm{PH} 04$ & 4 & 4 & 4 & 4 & 4 & 4 \\
\hline & \multirow[t]{2}{*}{ Colour staining } & $\mathrm{PH} 02$ & 5 & 5 & 5 & 5 & 5 & 5 \\
\hline & & $\mathrm{PH} 04$ & 5 & 5 & 5 & 5 & 5 & 5 \\
\hline
\end{tabular}

\section{Antimicrobial efficacy}


Next, the antimicrobial activities of cotton fabrics coated with PHMB were qualitatively evaluated after dyeing with acid dyes against two selected model bacteria, i.e., S. aureus and K. pneumoniae, as shown in Fig. 6. Table 4 presents the inhibition zone $(\mathrm{mm})$. Clearly, the cotton fabrics coated with PHMB exhibit a stronger inhibition against gram-positive $S$. aureus, with the inhibition zone going up to $0.58 \mathrm{~mm}$, as compared with the pristine control sample. By contrast, $K$. pneumoniae shows an obvious resistance to $\mathrm{PHMB}$, and the inhibition zone was merely at $0.05 \mathrm{~mm}$, far less than that of $S$. aureus. After dyeing with C.I. Acid Blue 83, the inhibition zone against $S$. aureus was reduced to $0.47 \mathrm{~mm}$, whereas regarding C.I. Acid Red 127 and C.I. Acid Black 172, the inhibition zone against S. aureus dropped to 0.33 and 0.06 , respectively. Regarding K. pneumoniae, inhibition zone for the three acid dyes declined to zero. Despite this, the growth of $K$. pneumoniae traversing the fabric samples was inhibited. This indicates that dyeing can weaken the antimicrobial activities of PHMB-treated cotton fabrics. The reason is closely associated with the strong ion-ion bonding between positively charged PHMB molecules and negatively charged dye molecules, which neutralises PHMB and thus diminishes its bactericidal action.

Table 4

The inhibition zone $(\mathrm{mm})$ of cotton fabrics treated with PHMB after dyeing with three acid dyes in inhibiting $S$. aureus $(S A)$ and $K$. pneumoniae $(K P)$

\begin{tabular}{|c|c|c|c|c|c|c|}
\hline \multirow[t]{2}{*}{ Samples } & & \multirow[t]{2}{*}{ Control } & \multirow[t]{2}{*}{$\mathrm{PHO4}$} & \multicolumn{3}{|c|}{ PH04-500 } \\
\hline & & & & Red & Black & Blue \\
\hline \multirow[t]{2}{*}{ Inhibition zone/mm } & SA & 0 & 0.58 & 0.33 & 0.06 & 0.47 \\
\hline & $\mathrm{KP}$ & 0 & 0.05 & 0 & 0 & 0 \\
\hline
\end{tabular}

\section{Conclusions}

Textile industry discharges large quantities of wastewater generated in dyeing which results in severe pollution issues since there are substantial quantities of water and chemicals. The studies on ecologically sustainable and clean dyeing technology have aroused great interest among researchers and practitioners since the need to cut down generation and discharge of effluents from textile dyeing has become an important concern. The present study investigates the applicability and feasibility of cationic polyelectrolyte-based circular dyeing method using the typical cationic antimicrobial agent PHMB and anionic acid dyes. FTIR analysis confirms the presence of PHMB attached onto the surface of cellulosic fibres, as validated by the dyeing with acid dyes. The colour measurement shows that the colour strength is not only dependent upon the concentration of dyebath, but also relies on the content of PHMB coated on the fibres, suggesting the controllability of colour depth. PHMB treated fabric samples after dyeing have good/excellent colour levelness, and the colour fastness is basically satisfactory and acceptable. It was found that the dyebath is recyclable for circular dyeing, which implies that cationic polyelectrolytebased dyeing method may provide a practicable and promising strategy for ecologically sustainable dyeing to address the pollution issue of effluents discharged by the textile industry. Moreover, the dyeing can occur at room temperature which would greatly reduce consumption of heat energy in textile dyeing. 
Meanwhile, the bacteriostatic ability of dyed fabrics may be conducive to elimination or reduction of healthcare-associated infections that transmit through textiles. Based on the present study, the pilot-scale experiments are expected to be conducted to promote the industrial application of cationic electrolyte complex based circular coloration technology with recyclable dyebath.

\section{Declarations}

\section{Acknowledgement}

The authors gratefully appreciate financial support from The Hong Kong Polytechnic University for this work under the project of account code: ZVNM.

\section{Conflicts of interest}

The authors declare they have no financial interests.

Author contributions

Conceptualizaiton: Wen-Yi Wang, Chi-Wai Kan; Methodology: Wen-Yi Wang, Jia-Chi Chiou, Wan-Xue Chen, Jia-Li Yu; Formal analysis and investigation: Wen-Yi Wang, Chi-Wai Kan; Writing- original draft preparation: Wen-Yi Wang; Writing- review and editing: Chi-Wai Kan; Funding acquisition: Chi-Wai Kan; Resources: Chi-Wai Kan, Jia-Chi Chiou; Supervision: Chi-Wai Kan

\section{References}

1. Acharya S, Abidi N, Rajbhandari R, Meulewaeter F (2014) Chemical cationization of cotton fabric for improved dye uptake. Cellulose 21:4693-4706. https://doi.org/10.1007/s10570-014-0457-2

2. Ahmad A, Mohd-Setapar SH, Chuong CS, Khatoon A, Wani WA, Kumar R, Rafatullah M (2015) Recent advances in new generation dye removal technologies: novel search for approaches to reprocess wastewater. RSC Adv 5:30801-30818. https://doi.org/10.1039/c4ra16959j

3. Arivithamani N, Giri Dev VR (2018) Characterization and comparison of salt-free reactive dyed cationized cotton hosiery fabrics with that of conventional dyed cotton fabrics. J Clean Prod 183:579-589. https://doi.org/10.1016/j.jclepro.2018.02.175

4. Auerbach M (1943) Germicidal Quaternary Ammonium Salts in Dilute Solution A Colorimetric Assay Method. Ind Eng Chem Anal Ed 15:492-493. https://doi.org/10.1021/i560120a006

5. Bhaskara U, Sanders Y, Gooijer H, Warmoeskerken M (2021) Kinetics of Adsorption and Desorption of PHMB from Textile Surfaces. AATCC J Res 8:1-7. https://doi.org/10.14504/ajr.8.1.1

6. Blackburn RS, Harvey A, Kettle LL, Payne JD, Russell SJ (2006) Sorption of poly (hexamethylenebiguanide) on cellulose: mechanism of binding and molecular recognition. Langmuir 22:5636-5644. https://doi.org/10.1021/la053002b 
7. Burkinshaw SM, Salihu G (2019) The role of auxiliaries in the immersion dyeing of textile fibres: Part 3 theoretical model to describe the role of inorganic electrolytes used in dyeing cellulosic fibres with direct dyes. Dyes Pigments 161:546-564. https://doi.org/10.1016/j.dyepig.2017.11.039

8. Cai L, Ying D, Liang X, Zhu M, Lin X, Xu Q, Cai Z, Xu X, Zhang L (2021) A novel cationic polyelectrolyte microsphere for ultrafast and ultra-efficient removal of heavy metal ions and dyes. Chem Eng $\mathrm{J} 410$. https://doi.org/10.1016/j.cej.2021.128404

9. Cao Y, Gu J, Wang S, Zhang Z, Yu H, Li J, Chen S (2020) Guanidine-functionalized cotton fabrics for achieving permanent antibacterial activity without compromising their physicochemical properties and cytocompatibility. Cellulose. https://doi.org/10.1007/s10570-020-03137-2

10. Chen-Yu JH, Eberhardt DM, Kincade DH (2007) Antibacterial and laundering properties of AMS and PHMB as finishing agents on fabric for health care workers' uniforms. Cloth Text Res J 25:258-272. https://doi.org/10.1177/0887302X07303625

11. Chong CL, Li SQ, Yeung KW (1992) An objective method for the assessment of levelness of dyed materials. J Soc Dyers Colour 12:528-530. https://doi.org/10.16552/j.cnki

12. Correia J, Rainert KT, Oliveira FR, de Cássia SC, Valle R, Valle JAB (2020) Cationization of cotton fiber: an integrated view of cationic agents, processes variables, properties, market and future prospects. Cellulose. https://doi.org/10.1007/s10570-020-03361-w

13. Dasgupta J, Sikder J, Chakraborty S, Curcio S, Drioli E (2015) Remediation of textile effluents by membrane-based treatment techniques: a state of the art review. J Environ Manage 147:55-72. https://doi.org/10.1016/j.jenvman.2014.08.008

14. Dong W, Zhou M, Li Y, Zhai S, Jin K, Fan Z, Zhao H, Zou W, Cai Z (2020) Low-salt dyeing of cotton fabric grafted with $\mathrm{pH}$-responsive cationic polymer of polyelectrolyte 2-(N,N-dimethylamino)ethyl methacrylate. Colloid Surface A 594. https://doi.org/10.1016/j.colsurfa.2020.124573

15. Fang L, Zhang X, Ma J, Sun D, Zhang B, Luan J (2015) Eco-friendly cationic modification of cotton fabrics for improving utilization of reactive dyes. RSC Adv 5:45654-45661. https://doi.org/10.1039/c5ra05887b

16. Fang L, Zhang X, Sun D (2013) Chemical modification of cotton fabrics for improving utilization of reactive dyes. Carbohyd Polym 91:363-369. https://doi.org/10.1016/j.carbpol.2012.08.049

17. Furlan FR, de Melo da Silva LG, Morgado AF, de Souza AAU, Guelli Ulson de Souza SMA (2010) Removal of reactive dyes from aqueous solutions using combined coagulation/flocculation and adsorption on activated carbon. Resour Conserv Recy 54:283-290. https://doi.org/10.1016/j.resconrec.2009.09.001

18. Gao Y, Yu X, Pierlot AP, Denning RJ, Cranston R (2011) A simultaneous antimicrobial and shrink resistance treatment of wool woven fabrics using the polymeric biocide polyhexamethylene biguanide. J Mater Sci 46:3020-3026. https://doi.org/10.1007/s10853-010-5180-2

19. Khatri A, Peerzada MH, Mohsin M, White M (2015) A review on developments in dyeing cotton fabrics with reactive dyes for reducing effluent pollution. J Clean Prod 87:50-57. https://doi.org/10.1016/j.jclepro.2014.09.017 
20. Ma W, Du S, Yan S, Yu X, Zhang Z, Zhang S (2020) Salt-Free Dyeing of Modified Cotton through Graft Polymerization with Highly Enhanced Dye Fixation and Good Strength Properties. Polymers 12. https://doi.org/10.3390/polym12020462

21. Meka VS, Sing MKG, Pichika MR, Nali SR, Kolapalli VRM, Kesharwani P (2017) A comprehensive review on polyelectrolyte complexes. Drug Discov Today 22:1697-1706. https://doi.org/10.1016/j.drudis.2017.06.008

22. Mu B, Li W, Xu H, Emanuel L, Yang Y (2019) Salt-free and environment-friendly reactive dyeing of cotton in cottonseed oil/water system. Cellulose 26:6379-6391. https://doi.org/10.1007/s10570019-02541-7

23. Nallathambi A, Venkateshwarapuram RGD (2017) Industrial scale salt-free reactive dyeing of cationized cotton fabric with different reactive dye chemistry. Carbohyd Polym 174:137-145. https://doi.org/10.1016/j.carbpol.2017.06.045

24. Nand V, Ellwood MJ (2018) A simple colorimetric method for determining seawater alkalinity using bromophenol blue. Limnol Oceanogr-Meth 16:401-410. https://doi.org/10.1002/lom3.10253

25. Ozturk E, Cinperi NC, Kitis M (2020) Improving energy efficiency using the most appropriate techniques in an integrated woolen textile facility. J Clean Prod 254. https://doi.org/10.1016/j.jclepro.2020.120145

26. Sakai T (1983) Spectrophotometric determination of trace amounts of quaternary ammonium salts in drugs by ion-pair extraction with bromophenol blue and quinine. Analyst 108:608-614. https://doi.org/10.1039/AN9830800608

27. Simoncic B, Tomsic B (2010) Structures of Novel Antimicrobial Agents for Textiles - A Review. Text Res J 80:1721-1737. https://doi.org/10.1177/0040517510363193

28. Song C, Zhao J, Li H, Liu L, Li X, Huang X, Liu H, Yu Y (2018) One-Pot Synthesis and Combined Use of Modified Cotton Adsorbent and Flocculant for Purifying Dyeing Wastewater. ACS Sustain Chem Eng 6:6876-6888. https://doi.org/10.1021/acssuschemeng.8b00713

29. Sun S, Gao B, Yue Q, Li R, Song W, Bu F, Zhao S, Jia R, Song W (2016) Comparison of epichlorohydrin-dimethylamine with other cationic organic polymers as coagulation aids of polyferric chloride in coagulation-ultrafiltration process. J Hazard Mater 307:108-118. https://doi.org/10.1016/j.jhazmat.2015.12.049

30. Vikrant K, Giri BS, Raza N, Roy K, Kim KH, Rai BN, Singh RS (2018) Recent advancements in bioremediation of dye: Current status and challenges. Bioresour Technol 253:355-367. https://doi.org/10.1016/j.biortech.2018.01.029

31. Wågberg L, Hägglund R (2001) Kinetics of polyelectrolyte adsorption on cellulosic fibers. Langmuir 17:1096-1103. https://doi.org/10.1021/la000629f

32. Wang P, Wang P, Guo Y, Rao L, Yan C (2021) Selective recovery of protonated dyes from dye wastewater by pH-responsive BCN material. Chem Eng J 412. https://doi.org/10.1016/j.cej.2021.128532 
33. Wang WY, Chiou JC, Chen WX, Yu JL, Kan CW (2021) Biosafety evaluation and quantitative determination of poly(hexamethylene biguanide) (PHMB) coated on cellulosic fabrics by KubelkaMunk equation. Cellulose 28:6651-6661. https://doi.org/10.1007/s10570-021-03939-y

34. Wang WY, Kan CW (2020) An eco-friendly dyeing method: bromophenol blue (BPB) applied for dyeing cotton fabrics coated with cationic finishing agents. Cellulose 27:9045-9059. https://doi.org/10.1007/s10570-020-03375-4

35. Wilts EM, Herzberger J, Long TE (2018) Addressing water scarcity: cationic polyelectrolytes in water treatment and purification. Polym Int 67:799-814. https://doi.org/10.1002/pi.5569

36. Worsley A, Vassileva K, Tsui J, Song W, Good L (2019) Polyhexamethylene Biguanide:Polyurethane Blend Nanofibrous Membranes for Wound Infection Control. Polymers (Basel) 11. https://doi.org/10.3390/polym11050915

37. Xie W, Zhang M, Liu D, Lei W, Sun L, Wang X (2016) Reactive Yellow 161 Decolorization by TiO2/Porous Boron Nitride Nanosheet Composites in Cotton Dyeing Effluent. ACS Sustain Chem Eng 5:1392-1399. https://doi.org/10.1021/acssuschemeng.6b01896

38. Yagub MT, Sen TK, Afroze S, Ang HM (2014) Dye and its removal from aqueous solution by adsorption: a review. Adv Colloid Interface Sci 209:172-184.

https://doi.org/10.1016/j.cis.2014.04.002

39. Zahrim AY, Tizaoui C, Hilal N (2011) Coagulation with polymers for nanofiltration pre-treatment of highly concentrated dyes: A review. Desalination 266:1-16. https://doi.org/10.1016/j.desal.2010.08.012

40. Zhao W, Jiao Y, Gao R, Wu L, Cheng S, Zhuang Q, Xie A, Dong W (2020) Sulfonate-grafted conjugated microporous polymers for fast removal of cationic dyes from water. Chem Eng J 391. https://doi.org/10.1016/j.cej.2019.123591

\section{Figures}

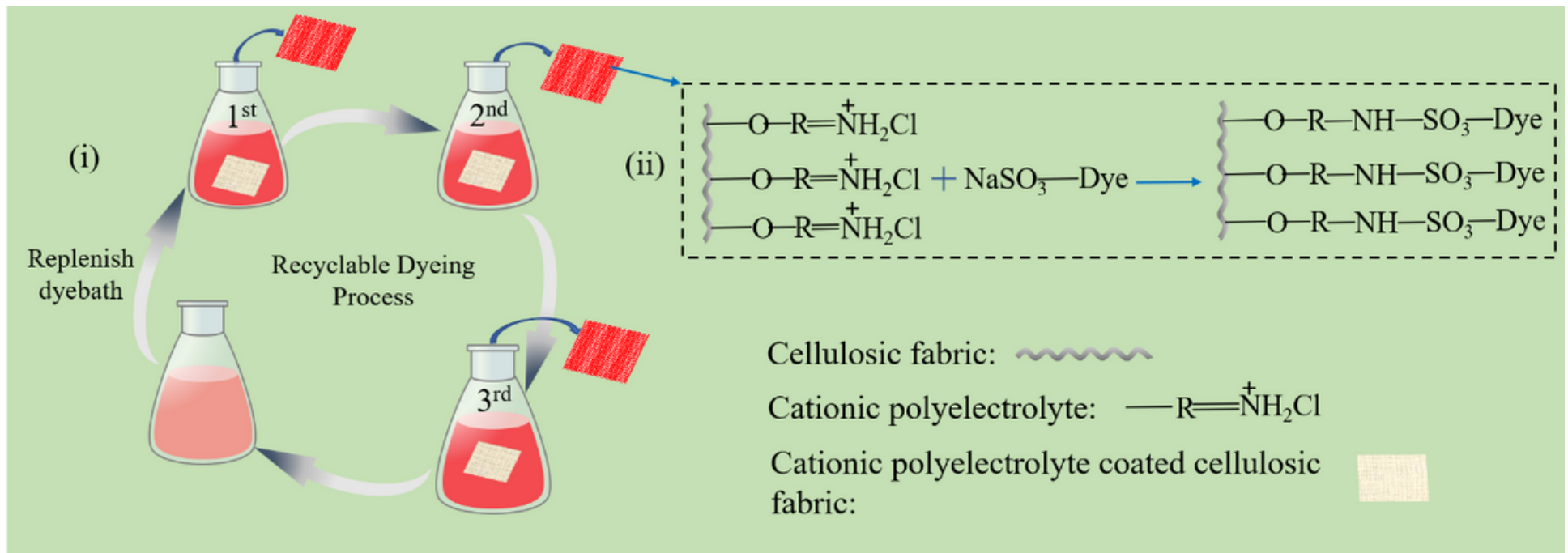


(i) Schematic diagram of the proposed recyclable dyeing process based on cationic polyelectrolyte; and (ii) The dyeing mechanism between anionic dye molecules and cationic polyelectrolyte treated cellulosic fabric

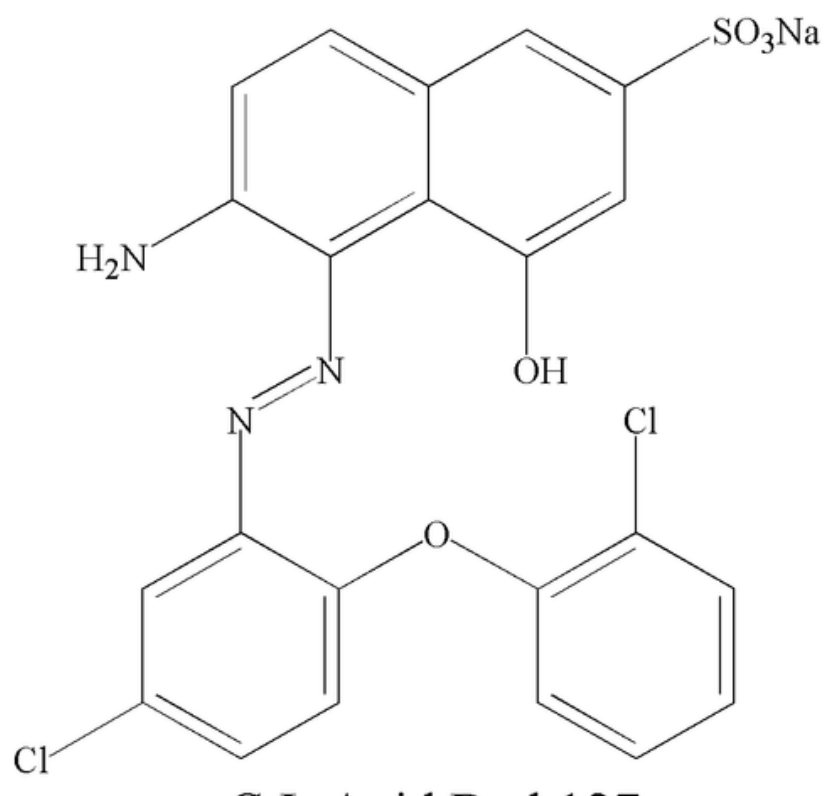

C.I. Acid Red 127

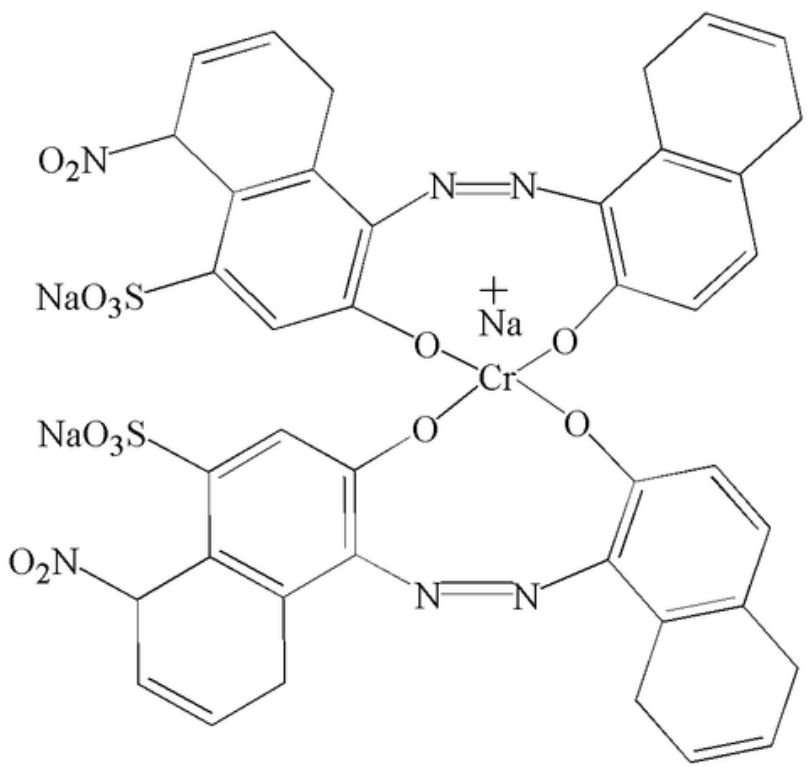

C.I. Acid Black 172

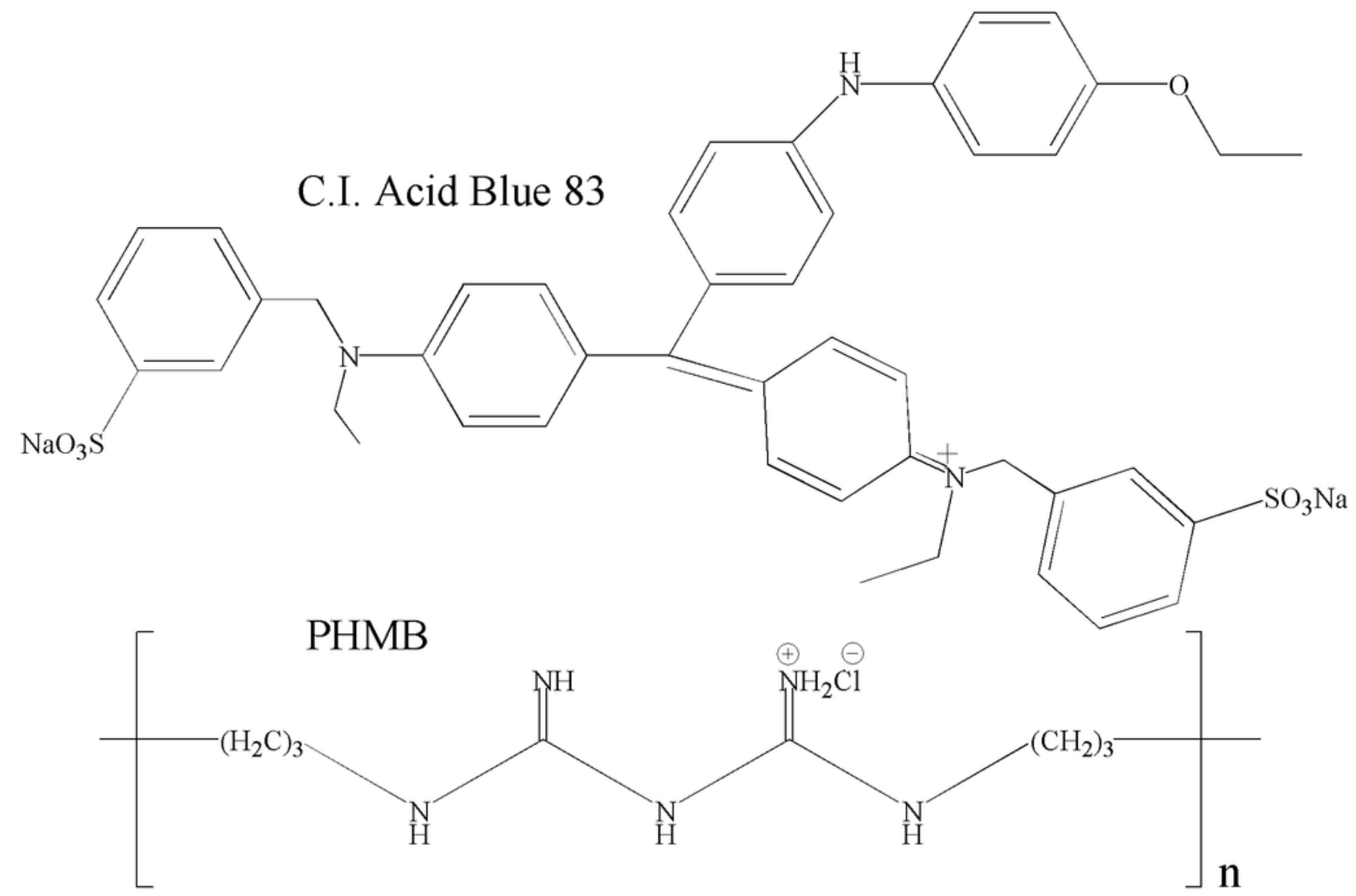

Figure 2

Chemical structures of C.I. Acid Red 127, C.I. Acid Black 172, C.I. Acid Blue 83 and PHMB 


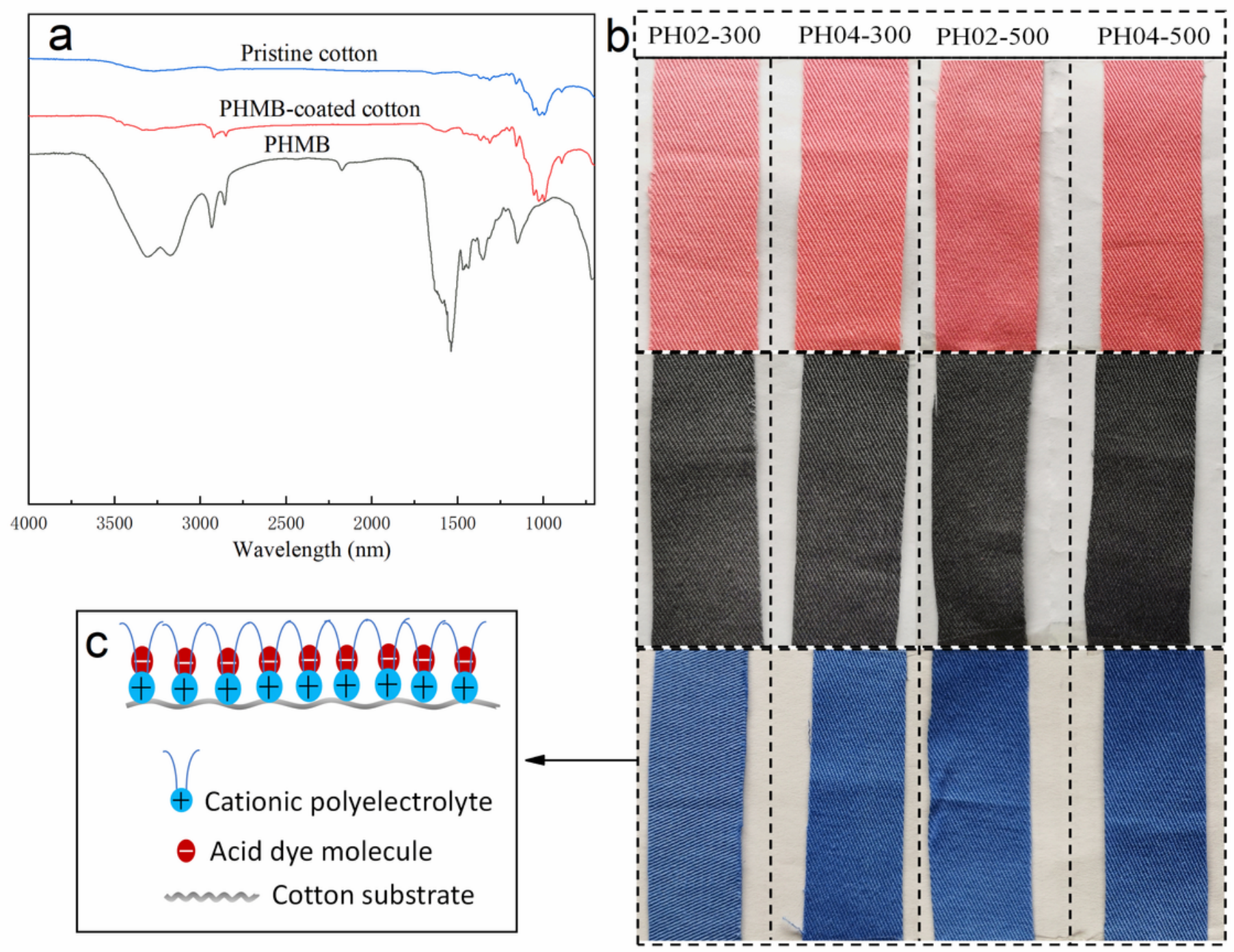

Figure 3

(a) FTIR spectra of pristine cotton fabric, PHMB, and the cotton fabric treated with PHMB; (b) colour shades of PHMB treated cotton fabric dyed with C.I. Acid Red 127, C.I. Acid Black 172 and C.I. Acid Blue 83 , respectively; and the underlying dyeing mechanism between acid dye molecules and PHMB-coated cotton fabric (c) 

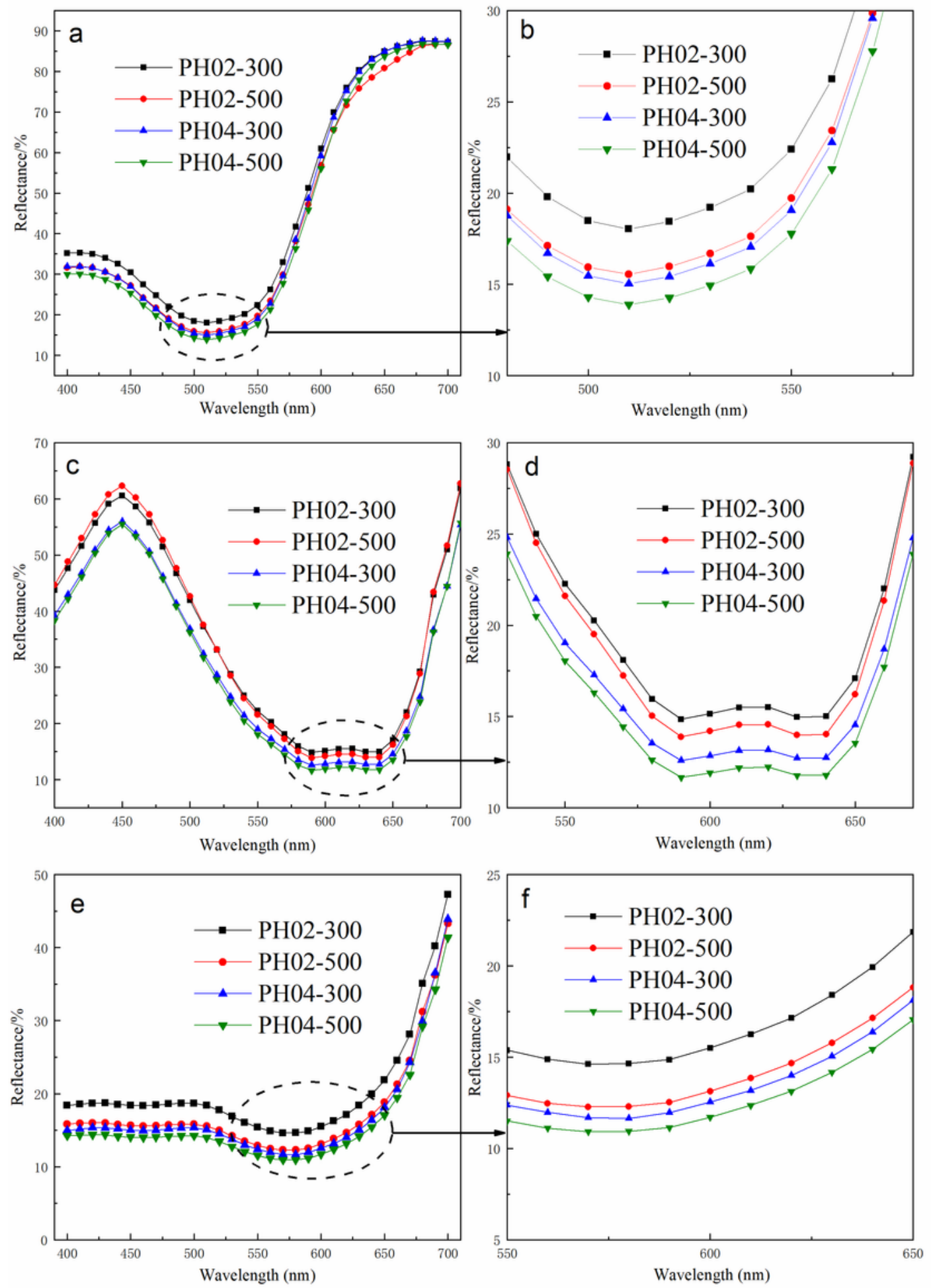

Figure 4

The reflectance curves of PHMB treated cellulosic fabrics dyed with C.I. Acid Red 127 (a); C.I. Acid Blue 83 (c); and C.I. Acid Black 172 (e); and the corresponding enlarged maximum adsorption peaks (b, d, f), respectively 

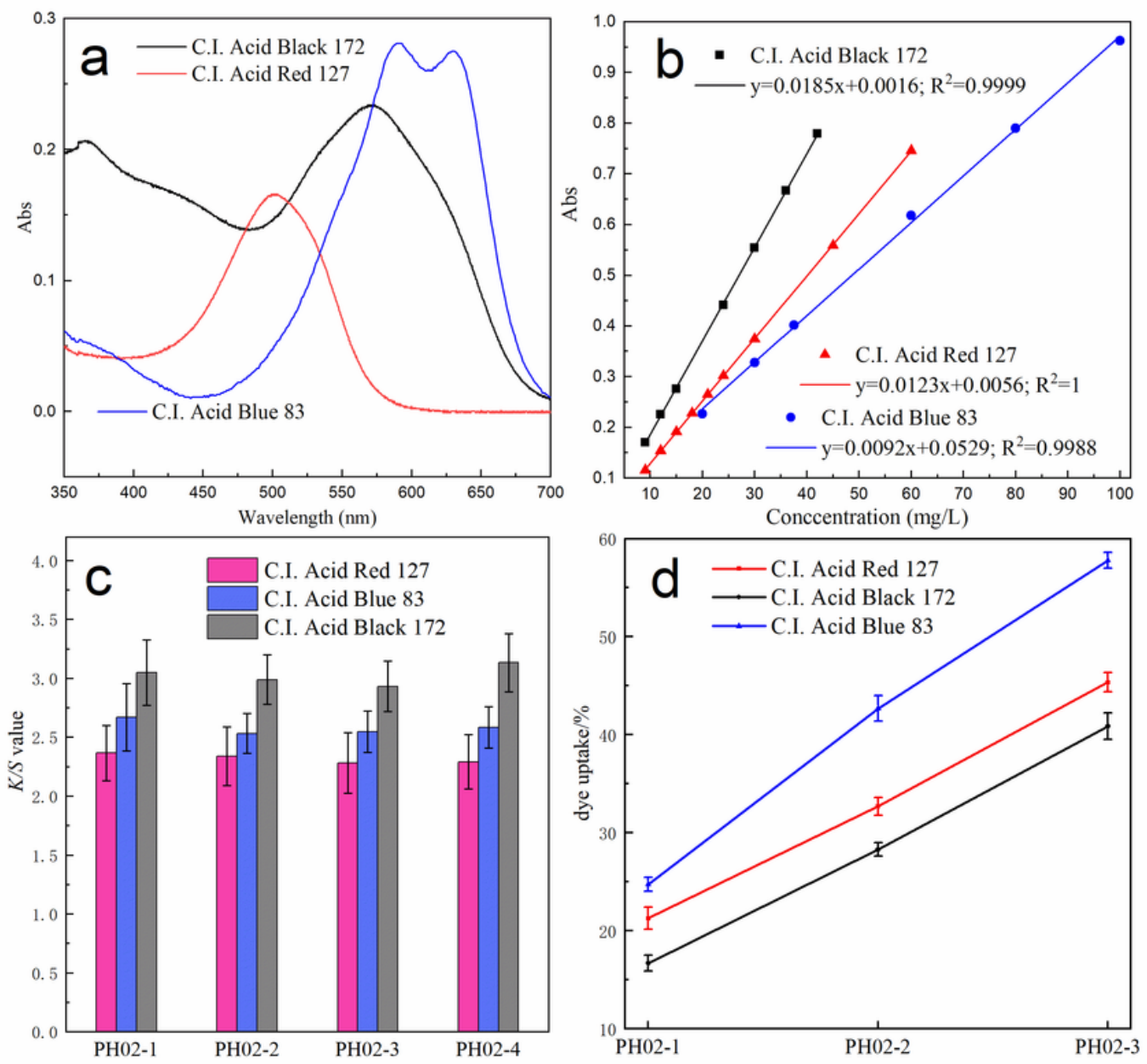

\section{Figure 5}

Absorbance curves of the three model acid dyes in aqueous solution in the range of UV-visible spectrum (a); the corresponding calibration curves established at maximum absorption peaks (b); (c) displays colour yields of PHMB treated cotton fabrics after being dyed with recycled dyebaths; and dye uptake of three model acid dyes after being dyed with recycled dyebaths $(d)$ 


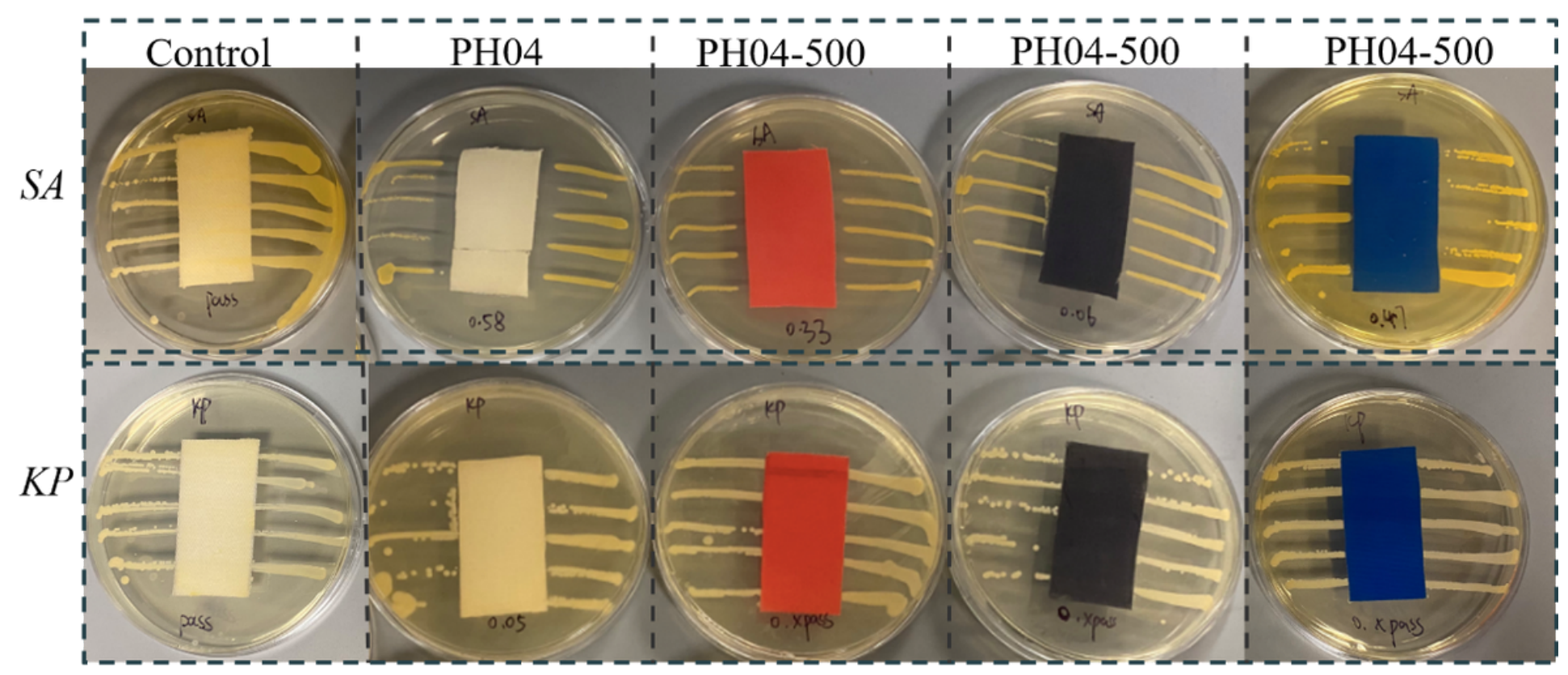

Figure 6

Antimicrobial activities against S. aureus (SA) and K. pneumoniae (KP) of cotton fabrics treated with PHMB after dyeing with three acid dyes 